\title{
ABORdAGEM DIAGNÓSTICA E TERAPÊUTICA NA INFECÇÃO DO TRATO URINÁRIO - ITU
}

\author{
Ita Pfeferman Hellberg*, Nestor Schor \\ Trabalho realizado na Disciplina de Nefrologia da UNIFESP; \\ Ambulatório de Infecção Urinária da Universidade Federal de São Paulo
}

\begin{abstract}
RESUMO - Os autores revisam aspectos recentes no diagnóstico e no tratamento clínico de infecção do trato urinário. As diferentes formas de apresentação da ITU como cistite, pielonefrite, síndrome uretral bem como a relevância clínica da bacteriúria assintomática, contaminação e bacteriúria de baixa contagem são comentadas. Abordam-se os aspectos fisiopatogênicos relacionados à virulência da bactéria e também os fatores predisponentes do hospedeiro à ITU como obstrução do trato urinário, refluxo vesico-ureteral, cateterização urinária, gravidez, diabetes mellitus, atividade sexual, métodos contraceptivos, prostatismo, menopausa, idade avançada e transplante renal. Os critérios diagnósticos de ITU e os
\end{abstract}

principais exames laboratoriais utilizados na diferenciação entre ITU do trato urinário baixo ou alto foram revistos. Os autores concluem que é importante a compreensão destes diferentes aspectos no manuseio e também na prevenção da recorrência em pacientes com ITU e que os diferentes esquemas terapêuticos estabelecidos de acordo com grupos específicos de pacientes com ITU maximizam os benefícios terapêuticos, além de reduzir os custos e as incidências de efeitos adversos.

UNITERMOS: Infecção urinária. Bacteriúria assintomática. Pielonefrite. Cistite. Síndrome uretral.

\section{INTRODUÇÃo}

A infecção do trato urinário (ITU) é uma patologia extremamente freqüente, que ocorre em todas as idades, do neonato ao idoso, mas durante o primeiro ano de vida, devido ao maior número de malformações congênitas, especialmente válvula de uretra posterior; acomete preferencialmente 0 sexo masculino. A partir deste período, durante toda a infância e principalmente na fase pré-escolar, as meninas são acometidas por ITU 10 a 20 vezes mais do que os meninos. $\mathrm{Na}$ vida adulta, a incidência de ITU se eleva e o predomínio no sexo feminino se mantém, com picos de maior acometimento no início ou relacionado à atividade sexual, durante a gestação ou na menopausa, de forma que $48 \%$ das mulheres apresentam pelo menos um episódio de ITU ao longo da vida'. Na mulher, a susceptibilidade à ITU se deve à uretra mais curta e a maior proximidade do ânus com o vestíbulo vaginal e uretra. No homem, o maior comprimento uretral, maior fluxo urinário e o fator antibacteriano

\footnotetext{
*Correspondência: Universidade Federalde SãoPaulo(UNIFESP) Escola Paulista de Medicina,

R. Botucatu 740-CEP: 04023-900-São Paulo-SP Brasil-Tel:(11)55746300-Fax:(11) 55739652
}

prostático são protetores. O papel da circuncisão é controverso, mas a menor ligação de enterobactérias à mucosa do prepúcio pode exercer proteção contra ITU. A partir da $5^{\mathrm{a} a}$ $6^{a}$ década, a presença do prostatismo torna o homem mais suscetível à ITU.

AITU é classificada como não complicada quando ocorre em paciente com estrutura e função do trato urinário normais e é adquirida fora de ambiente hospitalar. As condições que se associam à ITU complicada incluem as de causa obstrutiva (hipertrofia benigna de próstata, tumores, urolitíase, estenose de junção uretero-piélica, corpos estranhos, etc); anátomofuncionais (bexiga neurogênica, refluxo vesico-ureteral, rim-espongiomedular, nefrocalcinose, cistos renais, divertículos vesicais); metabólicas (insuficiência renal, diabetes mellitus, transplante renal); uso de catéter de demora ou qualquer tipo de instrumentação; derivações ileais. Aavaliação urológica em ITU deve ser indicada em neonatos e crianças, infecção persistente após $72 \mathrm{~h}$ de terapia, ITU recorrente em homens ou em transplantados renais e também em mulheres com reinfecções freqüentes.

Existe consenso de que os microorganismos uropatogênicos como a Escherichia Coli colonizam o cólon, a região perianal, enas mulheres, o intróito vaginal e a região perianal. Posteriormente, processa-se a ascenção facul- tativa para bexiga e/ou rins, pois em condições normais há competição entre estes microorganismos com a flora vaginal e perineal.

O espectro clínico de ITU é muito amplo reunindo diferentes condições:

Cistite: a aderência da bactéria à bexiga leva ao quadro de cistite bacteriana, ou infecção do trato urinário "baixo". A contagem de bactérias deveria permitir uma clara distinção entre contaminação e infecção. Entretanto, a utilidade e consistência do critério de Bacteriúria significante $\mathrm{como}^{3} 10^{5}$ unidades formadoras de colônias por mililitro (UFC/mL) para o diagnóstico de ITU tem sido freqüentemente questionadas. A valorização dos sintomas de ITU, conforme descrição a seguir, deve prevalecer, e portanto nos casos sintomáticos, contagens $^{3} 10^{4} \mathrm{UFC} / \mathrm{mL}$ ou até menores, dependendo do germe, podem sugerir ITU.

Pielonefrite (PN) aguda : também denominada de infecção do trato urinário "alto" ou nefrite intersticial bacteriana, por refletir alterações anatômicas e/ou estruturais renais, decorrentes deum processo inflamatório agudo acometendo o rim e suas estruturas adjacentes. A PN aguda não complicada pode acometer as mesmas muIheres que desenvolvem cistite, mas a proporção dePN para cistiteéde 18: I ou 28: I. Clinicamente, a PN costuma se diferenciar da cistite pela presença de sintomas clínicos mais exuberantes esistêmicos, conforme será descrito adiante. 
Bacteriúria de baixa contagem: Baixa contagem pode significar contaminação, mas na grande maioria dos casos os germes isolados são típicos de ITU, como E. coli, outros gram-negativos ou o Staphylococcus saprophyticus. Portanto, a baixa contagem pode também refletir: a) fase precoce de ITU em andamento; b) diluição urinária devido a maior ingestão de líquidos; c) crescimento lento de certos uropatógenos como o Staphylococcus saprophyticus ou ainda d) síndrome uretral (vide descrição a seguir).

Bacteriúria assintomática: Presença de bacteriúria na ausência de sintomas. Para considerá-la significante e diferenciá-la de contaminação são necessárias pelo menos duas uroculturas em que o mesmo germe foi isolado e com contagem $\geq 10^{5} \mathrm{UFC} / \mathrm{mL}$ ou próximas a este valor. Para ITU por $S$. saprophyticus ou Cândida, "cutoff" (valor de corte) de $10^{4} \mathrm{UFC} / \mathrm{mL}$ é aceito. $O$ tratamento desta condição é controverso, conforme será comentado adiante.

Síndrome Uretral ${ }^{2}$ ou Síndrome PiúriaDisúria ou "Abacteriúria sintomática": diferentemente da condição anterior, os sintomas de disúria e maior freqüência urinária são exuberantes, mas não se acompanham de urocultura positiva e sim por sedimento urinário normal ou com leucocitúria (leucocitúria estéril). Podem significar: a) infecções por germes fastídicos ou não habituais (não crescem nos meios de cultura habituais) como a Chlamydia trachomatis, Ureaplasma urealyticum, Neisseria gonorrhoeae, Mycoplasma, Mycobacteria, Trichomonas, Candida ; b) abscesso renal sem drenagem para o trato urinário; c) tuberculose do trato urinário, mais freqüente nos últimos anos; d) amostras urinárias obtidas durante tratamento ou durante uso de agentes antisépticos. É muito importante o diagnóstico diferencial com vaginites, vulvites, uretrites e outras causas de cistite não bacteriana como as virais, fúngicas, por tumores, corpos estranhos, radiação, químicas (ciclofosfamida, etc), imunológicas, entre outras. Ressalta-se também a necessidade de diagnóstico diferencial com Cistite Intersticial decorrente de um defeito nos glicosaminoglicanos da camada de mucina que reveste o uroepitélio vesical e cujo diagnóstico só é realizado através de cistoscopia com achado de úlceras de Hunner ou glomerulações.
Contaminação: É mais provável em presença de baixíssimas contagens bacterianas ou crescimento de mais de um microorganismo. Streptococcus $\alpha$-hemolíticos, Lactobacilos, Gardnerella, espécies de Corynebacteria são considerados contaminantes vaginais e uretrais. Infecção polimicrobiana verdadeira é rara, exceto em pacientes com derivações ileais, bexiga neurogênica, fístula vesicocólica, abscessos crônicos ou catéteres de demora.

\section{Patogenia}

A freqüência dos germes causadores de ITU varia na dependência de onde foi adquirida a infecção, intra ou extra-hospitalar e também difere em cada ambiente hospitalar considerado. Os maiores responsáveis pela ITU são os germes gram-negativos entéricos especialmente a E.coli, que é o mais freqüente independente da série estudada, seguido dos demais gram-negativos como Klebsiella, Enterobacter, Acinetobacter, Proteus, Pseudomonas, etc. Além destes, na maioria das séries americanas, o Staphylococcus saprophyticus, um germe gram-positivo, tem sido apontado como segunda causa mais freqüente de ITU não complicada. $O$ diagnóstico de ITU por $S$. saprophyticus é por vezes difícil, pelo fato de apresentar um crescimento muito lento em urocultura (vide acima em causas de bacteriúria de baixa contagem) e também porque este agente pode ser confundido com outro staphylococcus coagulase e DNAse-negativo, saprófita da flora comensal do trato urinário, mucosas e pele, como o Staphylococcus epidermidis. O que o diferencia deste último é a resistência ao antibiótico Novobiocina e ao Ácido Nalidíxico. Nas ITU complicadas, a incidência de Pseudomonas é maior e de gram-positivos resistentes como Enterococcus também.

Existem fatores de virulência da bactéria que influenciam o grau de acometimento na infecção ${ }^{3}$. As enterobactérias se caracterizam pela presença ou não das seguintes estruturas: a) flagelo ou antígeno " $H$ ", responsável pela motilidade da bactéria; b) cápsula ou antígeno "K", que confere resistência à fagocitose; c) polissacarídios ou antígeno "O" sempre presentes na membrana externa da bactéria, que são determinantes antigênicos de anticorpos específicos sendo, portanto, úteis na tipagem sorológica ( 150 antígenos " 0 " definidos) e na discriminação entre relapso e reinfecção; d) fímbrias ou pili ou adesinas, responsáveis pela adesão da bactéria ao urotélio e transmissão de informação genética a outras bactérias via DNA dos plasmídeos. Existem dois tipos de pili: tipol (manose-sensível) cujos receptores são a manose ou a proteína de Tamm-Horsfall e tipo 2 (manose-resistente) cujo receptor é parte de um glicoesfingolípide (Gal-Gal). Os fagócitos do hospedeiro, incluindo polimorfonucleares neutrófilos e macrófagos, reconhecem os pili tipo le são capazes de fagocitar e matar a bactéria na ausência de anticorpo específico. É possível que anticorpos contra pili tipo I diminuam a resistência à infecção eé por esta razão que este antígeno não deve ser incorporado a uma eventual vacina. Bactérias que possuem pili tipo II aderem ao urotélio e também a antígenos do grupo sangüíneo tipo $P$. Isto se deve à presença de antígenos do grupo sangǘneo $P$ na superfície de uroepitélio. Devido à similaridade antigênica entre bactérias gram-negativas e este ou outros grupos sangüíneos (Lewis, $A B O$ ), a determinação de fenótipos relacionados aos grupos sangüíneos serve como marcação de populações com risco de desenvolverem ITU de repetição.

Existem também vários fatores predisponentes do hospedeiro que participam na patogenia da ITU ${ }^{4}$ :

Obstrução do trato urinário: a estase urinária leva a condições propícias de proliferação bacteriana e a própria distensão vesical reduz a capacidade bactericida da mucosa.

Refluxo vésico-ureteral: inserção lateral do ureter na bexiga, sem constrição adequada durante a contração do detrusor, permitindo refluxo de urina durante a micção e manutenção de posterior volume residual, propício à proliferação de bactérias ${ }^{5}$.

Cateterização urinária: cateteres de demora predispõem à bacteriúria significante (geralmente assintomática), especialmenteem condição de drenagem aberta (ITU em 48 hs), e o risco de bacteriemia por gram-negativo que já é de cinco vezes, é proporcional ao tempo de cateterização. A leucocitúria não tem uma boa correlação com presença de ITU em pacientes com catéter. Além de crescerem em suspensão, algumas bactérias produzem uma matriz de polissacáride ou "biofilme" que as envolve e protege das defesas do hospedeiro, e também confere resistência aos antimicrobianos utilizados $^{6}$. Adicionalmente, a pre- 
sença degermes neste biofilme cria umambiente favorávelàformaçãodeencrustrações nasuperfície interna do catéter, levando à obstrução.

Gravidez: a prevalência de bacteriúria assintomática é de até $10 \%$ na gravidez, podendo ser observada do início da gestação ao $3^{\circ}$ trimestre e 25 a $57 \%$ destas bacteriúrias não tratadas podem evoluir para infecção sintomática, inclusive pielonefrite, devido à dilatação fisiológica do ureter e pelve renal facilitando o refluxo. Há risco também de necrose papilar. A incidência de bacteriúria também aumenta em relação ao número prévio de gestações. ITU em gravidez se associa a um maior índice de prematuridade, baixo peso e mortalidade perinatal, além de maior morbidade materna. As alterações mecânicas e fisiológicas da gravidez que contribuem para ITU incluem: a) dilatação pélvica e hidroureter (vide comentários acima); b) aumento do tamanho renal $(\mathrm{l} \mathrm{cm}) \mathrm{c}$ ) modificação da posição da bexiga que se torna um órgão abdominal e não pélvico; d) aumento da capacidade vesical devido à redução do tônus vesical hormôniomediado; e) relaxamento da musculatura lisa da bexiga e ureter progesterona-mediados.

Diabetes Mellitus: não existem evidências de que freqüência de ITU sintomática seja maior em indivíduos diabéticos quando comparada a indivíduos normais do mesmo sexoe faixa etária. Existem relatos de maior frequência de bacteriúria assintomática entre mulheres diabéticas mas não entre homens diabéticos. A bacteriúria não se correlaciona com os níveis de hemoglobina glicosilada, e portanto com o controle da diabete, mas a presença de infecção certamente compromete tal controle. Existem várias alterações nos mecanismos de defesa do hospedeiro diabético, que o tornam mais suscetível às complicações decorrentes de ITU como: defeito no poder quimioterápico e fagocítico dos leucócitos polimorfonucleares devido ao ambiente hiperosmolar; doença microvascular levandoà isquemia tecidual local e fraca mobilização leucocitária e por fim, a neuropatia vesical (bexiga neurogênica). A infecção iatrogênica decorre da necessidade freqüente de hospitalização e cateterização nestes pacientes. $O$ papel da glicosúria ainda é muito discutido não tendo sido comprovada sua associação com maior colonização bacteriana até o presente momento. Certas complicações clínicas como pielonefrite enfisematosa ( $90 \%$ dos casos são diabéticos), abscesso perinéfrico e necrose papilar são muito mais comuns entre os diabéticos.

Relação Sexual / Métodos contraceptivos: a associação entre atividade sexual e cistite aguda (historicamente "cistite da lua de mel"), em decorrência da bacteriúria pós-coito, estábem estabelecida ${ }^{7}$. A menor ocorrência de bacteriúria assintomática entre celibatárias corroboram com a existência desta associação. $O$ uso do Diafragma e geléia espermicida como métodos contraceptivos também tem sido considerados fatores predisponentes à ITU. A presença do diafragma pode levar à uma discreta obstrução uretral que não se associa a maior risco de infecção. No entanto, quando da associação coma geléia espermicida, ocorrem alterações do $\mathrm{pH}$ e da flora vaginal (perda dos lactobacilos que mantém a acidez do $\mathrm{pH}$ vaginal) que podem favorecer a ascendência de germes ao trato urinário. $O$ uso de preservativos só propicia ITU quando contém espermicidas.

Prostatismo: a ocorrência de hipertrofia prostática benigna ou carcinoma de próstata traduzem uma situação de obstrução ao fluxo urinário com conseqüente esvaziamento vesical incompleto. Nestes casos a ITU decorre da presença de urina residual e também da necessidade mais freqüente de cateterização urinária. Menopausa: $O$ estrógeno estimula 0 crescimento e a proliferação da mucosa vaginal facilitando a remoção de bactérias. Adicionalmente, o estrógeno promove o acúmulo de glicogênio pelas células epiteliais, o que favorece o crescimento de lactobacilos que reduzem o $\mathrm{pH}$ vaginal tornando-o hostil para germes gram-negativos como as enterobactérias. Portanto, a falta de estrógeno na menopausa expõe a mulher a um maior risco de bacteriúria e ITU sintomática, pela redução do glicogênio, ausência de lactobacilos e elevação do $\mathrm{pH}$ vaginal. Sabe-se que a colonização vaginal por E. Coli é um pré-requisito para ascendência da bactéria ao trato urinário ${ }^{8}$. Em culturas seriadas de intróito vaginal, $56 \%$ de pacientes pós-menopausadas com ITU recorrente eram carreadoras de enterobactérias, especialmente de E. Coli .

Idade avançada: a frequiência de ITU aumenta com a idade em ambos os sexos. No homem idoso, além da doença prostática e suas implicações já descritas ${ }^{9}$, a ITU pode ser decorrente de estreitamento uretral e outras anormalidades anatômicas. Na mulher idosa, além da menopausa, alterações anátomofuncionais da bexiga relacionadas ou não à multiparidade, como cistocele, etc., o próprio acúmulo de infecções recorrentes, acabam por também aumentar a incidência de ITU nesta faixa etária. A própria infecção urinária estimula a hiperreflexia do detrusor e a endotoxina da $E$. Coli inibe as contrações $\alpha$-adrenérgicas uretrais reduzindo a pressão esfincteriana e resultando em incontinência urinária. Para ambos os sexos, a presença de patologias coexistentes como diabetes, acidentes vasculares cerebrais, demência, alterações na resposta imune e hospitalização e/ou instrumentação mais freqüente tornam a ITU mais prevalente nesta faixa etária

Transplante Renal: a prevalência de ITU no pós-transplante é de $35 \%$ a $80 \%$, sendo mais freqüente nos primeiros 3 meses após o transplante ${ }^{10}$. A maioria das ITU são assintomáticas (rim denervados) mas em $45 \%$ dos casos são recorrentes. Os agentes infecciosos podem ser adquiridos a partir do rim do doador, da ferida cirúrgica, do uso de cateteres urináriose do ambiente hospitalar. Microrganismos endógenos latentes podem também ser reativados devido ao uso de drogas imunossupressoras. $O$ risco de bacteriúria aumenta com o tempo de cateterização. No caso de ITU recorrente, investigação urológica ou pesquisa de refluxo urinário devem ser consideradas. Existem controvérsias quanto a uma possível aceleração no processo de rejeição crônica entre aqueles que apresentam ITU recorrente. Normalmente são causadas por bacilos gram-negativos e enterococcus. Entretanto, tem sido relatada ITU por Corynebacterium urealyticum em $10 \%$ dos casos contra $2 \%$ na população normal.

\section{Quadro clínico}

No indivíduo adulto os sintomas clínicos característicos de cistite são a disúria, polaciúria ou aumento da freqüência urinária, urgência miccional, dor em baixo ventre, arrepios de frio ou calafrios, com presença ou não de dor lombar. Podem fazer parte do quadro clínico mal-estar geral e indisposição. No indivíduo idoso é comum dor abdominal ou distúrbio de comportamento na ITU. Em crianças 
o principal sintoma pode ser dor abdominal" Em recém-nascidos, o diagnóstico clínico de ITU se torna suspeito quando na presença de icterícia fisiológica prolongada associada ou não à perda de peso (30\% dos casos), hipertermia, presença de complicações neurológicas (30\%), diarréia, vômitos ou cianose. Em lactentes, o déficit pôndero-estatural, diarréia ou constipação, vômitos, anorexia ou febre de etiologia obscura, podem levar à suspeita de ITU. Por fim, na faixa pré-escolar os sintomas podem ser febre, enurese, disúria ou polaciúria. No adulto, existe superposição entre os sintomas clínicos de ITU "baixa" vs "alta" (cistite vs pielonefrite). No entanto, a febreea dor lombar são muito mais comuns na pielonefrite, que se acompanha também de toxemia e queda do estado geral mais importante. Laboratorialmente, também tenta-se distingui-las como será comentado a seguir.

\section{Diagnóstico Laboratorial}

Fitas reagentes ("dipstick"): são especialmente úteis na triagem de casos agudos suspeitos de ITU, principalmente em nível ambulatorial ou no consultório. As fitas detectam esterase leucocitária (indicativa de piúria) ou atividade redutora de nitrato. A redução de nitrato para nitrito é tempo-dependente esóé positiva em ITU causada por enterobactérias pois só elas apresentam esta atividade. O valor negativo da fita é o mais importante, pois quando negativas praticamente excluem ITU. Eritrócitos e leucócitos são lisados em urinas com pH > 6,0, com reduzida osmolaridade ou em análises tardias. Portanto, falso negativo na fita é mais difícil do que na microscopia. 0 $\mathrm{pH}$ urinário $>7,5$, detectado por fitas reagentes também sugere fortemente ITU.

Sedimento urinário: o exame microscópico é feito após centrifugação da urina a) Leucocitúria: são consideradas anormais, contagens superiores a 10.000 leucócitos $/ \mathrm{ml}$ ou 10 leucócitos/campo, independentemente da morfologia destes leucócitos. Em laboratórios que se utilizam de tecnologia mais avançada, onde o exame microscópico de urina é realizado através de citometria de fluxo, contagem de leucócitos de até $30.000 / \mathrm{ml}$ são consideradas normais em mulheres. A presença de leucocitúria não é diagnóstica de ITU devido a inúmeras causas de leucocitúria estéril como tuberculose, infecção por fungos, Chlamydia, Gonococcus, Lepstopira, Haemophilus, anae- róbios, vírus, etc. Dentre as leucocitúrias estéreis de origem não infecciosa se destacam a nefrite intersticial, litíase, presença de corpo estranho, rejeição de transplante, terapia com ciclofosfamida, trauma gênito-urinário, glomerulonefrite aguda e crônica, neoplasias, contaminação vaginal, etc.; b) Proteinúria: costuma ser discreta e variável; c) Hematúria: quando presente também é discreta. Como achado isolado está mais freqüentemente relacionada à presença de cálculos, tumores, tuberculose ou infecções fúngicas do trato urinário; d) $\mathrm{pH}$ - geralmente alcalino, exceto em infecção por micobactérias. Quando o $\mathrm{pH}$ é muito alcalino, superior a 8,0 pode sugerir infecção por Proteus; e) Bacteriúria: geralmente presente, mas necessitando sempre ser confirmada por cultura de urina; f) Cilindros leucocitários: sugerem pielonefrite.

Urocultura: A urina para urocultura deve ser obtida a partir do jato médio, e colhida através de técnicas assépticas, não em vigência de antibioticoterapia. Apesar da primeira urina da manhã conter potencialmente maior população de bactérias, devido ao maior tempo de incubação, a sintomatologia exuberante da ITU com elevada frequência urinária dificulta esta medida. Desta forma, a urina de qualquer micção pode ser valorizada desde que obtida com um intervalo de no mínimo duas horas após a micção anterior, período que corresponde ao tempo de latência para o crescimento bacteriano, para que se evitem falsos negativos. Em crianças procede-se a coleta em saco coletor. Se negativa quase que exclui ITU. Se duvidosa, pode-se confirmar através de punção suprapúbica. O número de colônias necessário para o diagnóstico de bacteriúria significanteé classicamente considerado como superior a $10^{5}$ colônias $/ \mathrm{ml}$ de urina. No entanto, progressivamente este critério tem sido questionado principalmente no que diz respeito à ITU. Em pacientes sintomáticos com contagens inferiores a esta, torna-se difícil excluir ITU (vide comentários acima sobre bacteriúria significante).

Exames para Diagnóstico diferencial entre ITU "baixa" "alta":

Imunofluorescência do Sedimento Urinário ou ACB ("Antibody-Coated Bacteria") : a base conceitual deste teste é de que a bactéria ao invadir o tecido leva à produção local de anticorpos que reagem com os antígenos de superfície da própria bactéria. Na realidade, mais do que um teste que diferencie ITU alta de baixa, o ACB é indicativo de comprometimento tissular (urotélio). É bastante específico mas não muito sensível. Falsos positivos são encontrados em prostatite, cistite hemorrágica, infecções muito recentes e especialmente, em crianças.

Outros exames: Teste de concentração urinária máxima; elevação de enzimas urinárias (b-glucuronidase, DHL-isoenzima 5 , $b_{2}$-microglobulinúria), sugestivas de defeitos tubulares, sugerem presença de pielonefrite. Outro exame inespecífico, mas não invasivo, que pode auxiliar no diagnóstico diferencial entre cistite e pielonefrite é a Proteína C-Reativa. A coleta de urina por sondagem vesical, após lavagem com antibióticos tipo neomicina ou polimixina, técnica de "washout", é sugerida por alguns autores, especialmente na ITU na infância (crianças com cistite terão urina estéril após esta lavagem).

A valorização de cada um destes exames diagnósticos foi revisada recentemente ${ }^{12}$.

\section{Imagem}

O diagnóstico por imagem é mais utilizado nos casos de ITU complicada, para identificar anormalidades que predisponham à ITU.

Ultra-som: útil para identificar presença de cálculos que podem estar associados com os quadros agudos de ITU ou mesmo propiciálos (ITU complicada), bem como a repercussão dos cálculos no trato urinário. Oultra-som éútil também na identificação de outras condições associadas a ITU como coleções, abscessos e rins policísticos.

Urografia Excretora (UGE): Não deve ser realizada na fase aguda de infecção, pois os resultados são pobres além da exposição à nefrotoxicidade. Em quase $85 \%$ das mulheres com ITU recorrente, a UGE é normal. Devido à reduzida sensibilidade deste exame, tem-se questionado bastante a validade da UGE em ITU a não ser na investigação de ITU complicada, para obter informações sobre alterações anatômicas como dilatação calicial, pélvica e ureteral, estenose de JUP, duplicidade pielocalicial e adequação do esvaziamento vesical ou identificar presença de obstrução ou cálculo. Deve-se salientar que no caso de suspeita de cálculos a própria Radiografia Simples de Abdome e/ou o ultrasom podem sugerir o diagnóstico. 
Uretrocistografia Miccional: Em crianças abaixo de dois anos com ITU recorrente, além da UGE, indica-se a uretrocistografia miccional (UCM), que é o "gold-standard" para o diagnóstico de Refluxo-Vesicoureteral (RVU). Em adultos não está indicada a não ser em ITU recorrente no pós-transplante para afastar refluxo ao rim transplantado.

Cintilografia com DMSA: A cintilografia com oácido dimercaptosuccínico(DMSA) marcado com Tecnécio $99\left({ }^{99 \mathrm{~m} T c}\right)$ tem sido muito utilizada no acompanhamento de crianças com RVU para detectar a presença de lesões corticais ou cicatriz renal secundária ao refluxo. Mais recentemente, o DMSA tem sido recomendado na fase aguda de ITU em crianças devido à sua maior sensibilidade em detectar danos corticais, auxiliando portanto no diagnóstico diferencial com pielonefrite.

Outros exames: a) Tomografia computadorizada (TC) é raramente necessária a não ser para descartar presença de abscesso perinefrético e também em casos de investigação de rins policísticos que podem estar associados com ITU; b) Cistoscopia: a cistoscopia não tem indicação na ITU não complicada e deve ser realizada somente em condições de urina estéril ou após profilaxia antibiótica. Em pacientes idosos e transplantados renais com ITU recorrente e hematúria, a cistoscopia está indicada para afastar câncer de bexiga.

\section{Tratamento}

Estratégias envolvendo diferentes esquemas terapêuticos de acordo com grupos específicos de pacientes com ITU maximizam os benefícios terapêuticos, além de reduzir os custos e as incidências de efeitos adversos ${ }^{13}$.

Cistite não complicada: vários agentes antimicrobianos por via oral podem ser usados para o tratamento da cistite ou ITU não complicada:

a) Sulfonamidas: dentre as sulfonamidas, quimioterápicos com ação bacteriostática, destaca-se a associação Sulfametoxazol-trimetoprim (SMZ-TMP) ou Cotrimoxazol, preferencialmente em formulações " $F$ " de $800 \mathrm{mg}$ de SMZ associados a $160 \mathrm{mg}$ de TMP para uso de I cp I2/I2hs, ou na posologia habitual de $2 \mathrm{cp}$ $12 / 12 \mathrm{hs}$.

b) Nitrofurantoína (Macrodantina), na dose de $100 \mathrm{mg} 6 / 6 \mathrm{hs})$.

c) Quinolonas: Ácido nalidíxico, $500 \mathrm{mg} 8 /$ 8hs, Ácido pipemídico, $400 \mathrm{mg} \mathrm{I2/12hs}$ d) "Novas" Quinolonas: Norfloxacina 400mg I2/12hs, Ciprofloxacina $250 \mathrm{mg} / 2 / 12 \mathrm{hs}$. Outras como a Lomefloxacina, Ofloxacina, Pefloxacina, etc. também podem ser utilizadas.

e) Cefalosporinas: A mais utilizada de I $^{\mathrm{a}}$ geração por via oral é a Cefalexina $250 \mathrm{mg} 6 /$ $6 \mathrm{hs}$ e das de $2^{\mathrm{a}}$ geração, o Cefaclor $250 \mathrm{mg}$ I2/ $12 \mathrm{hs}$. As cefalosporinas de $2^{\mathrm{a}}$ e $3^{\mathrm{a}}$ geração possuem espectro maior contra bactérias gram-negativas exceto enterococcus e a atividade contra pseudomonas é variável.

A sensibilidade aos antibióticos também varia dependendo da população estudada. Em avaliação realizada no ambulatório de ITU da Disciplina de Nefrologia da Universidade Federal de São Paulo, a maioria dos patógenos isolados mostrou-se menos sensível à associaçãoSMZ-TMP(resistência em torno de 30\%), fazendo com que as antigas e novas quinolonas fossem mais indicadas para tratamento de infecções não complicadas e também na profilaxia. Entretanto, existe variação quanto à sensibilidade aos antimicrobianos nos diferentes Serviços, e além disto, quando se trata de primeiro episódio de ITU, adquirida fora de ambiente hospitalar, a prescrição de SMZTMP deve ser considerada em primeira instância, pois é barata e bem tolerada. As novas quinolonas se constituiriam em droga de escoIha, pela facilidade na posologia (apenas duas tomadas diárias) seguida das cefalosporinas, no caso de resistência às quinolonas. Todos os antibióticos beta-lactâmicos comopenicilina $G$, ampicilina, amoxicilina, cefalexina, cefaclor são ativos contra os coliformes, mas as cefalosporinas atingem níveis urinários mais elevados. Deve-se reservar as quinolonas de maior espectro como a ciprofloxacina para uso em caso de impossibilidade de uso das outras drogas para não induzir resistência. Aciprofloxacina é especialmenteútil em pielonefrite de moderada severidade pois sua penetração tecidual é superior à da norfloxacina.

O grupo das Tetraciclinas (tetraciclina, oxitetraciclina, doxiciclina, minociclina) é especialmente efetivo no tratamento de infecções por Chlamydia Trachomatis (uretrite por Chlamydia deve ser tratada por 7 a 14 dias com Tetraciclina ou Sulfonamida) sendo portanto indicados em síndrome uretral e prostatite. As penicilinas resistentes à ação de germes produtores de penicilinase como oxacilina, cloxacilina e dicloxacilina se reservam ao tratamento de infecções estafilocócicas. Infecções por anaeróbios podem ser tratadas com metronidazol ou clindamicina. Deve-se ter em mente que a diluição urinária reduz a população bacteriana mas também a concentração do antibiótico, sendo que a micção remove ambos. Portanto, a eficácia ótima das drogas ocorre no período pós-miccional. As concentrações urinárias dos antibióticos refletem as presentes na medula renal sendo portanto melhores guias de eficácia do que as concentrações séricas, exceto quando da presença de insuficiência renal. As concentrações renais das drogas por sua vez, dependem do mecanismo de excreção renal, fluxo urinário, $\mathrm{pH}$ e função renal. Abscessos tendem a ter $\mathrm{pH}_{\mathrm{H}} \mathrm{pO}_{2}$ reduzidos, ea penetração antimicrobiana em cistos também é precária.

Recentemente, a duração ideal da terapia antibiótica em ITU tem sido reconsiderada. A utilização de dose única se justifica devido à superficialidade de infecção na mucosa em cistite bacteriana, concentração do antibiótico pelo rim resultando em níveis urinários extremamente elevados e pelo fato de quase $30 \%$ dos pacientes submetidos a lavagem vesical com solução de neomicina a $10 \%$ terem sido efetivamente tratados.

Dose única: a indicação mais apropriada de tratamento de ITU por dose única é em mulheres com a primeira ITU não complica$\mathrm{da}$, acometendo trato urinário inferior (cistite) já que seu uso inadvertido em ITU alta não reconhecida, mascara transitoriamente a progressão da infecção, com evolução potencial para pielonefrite. Dose única não é eficaz para o tratamento de ITU por Staphylococcus saprophyticus. Uma alternativa de antimicrobiano para a dose única para cistite por provável E. Coli, é a Fosfomicina Trometanol (3g) que porém tem pouca atividade sobre Klebsiella, Enterobacter, Acinetobacter, Proteus e Pseudomonas.

Tratamento de três dias: estudos controlados indicam que tratamentos curtos por três dias são os mais adequados ${ }^{14}$ no tratamento da ITU "baixa", com invasão superficial da mucosa, não complicada, com um ótimo balanço entre eficácia e incidência de efeitos colaterais, quando comparados com dose única ou aos cursos clássicos de 7 e 10 dias. Deve-se, no entanto, estar atento à recorrência, quando se utilizam cursos de três dias. $O$ resultado do curso de três dias é nitidamente superior à doseúnica. 
Hellberg IP et al.

Tratamento de sete dias: ITU em homem sempre deve ser tratada por sete dias e se a infecção persistir na urocultura de controle, mesmo após terapêutica adequada, devem ser investigados fatores complicadores. Pacientes com tratamento pregresso e alta probabilidade de ITU por germes resistentes também devem ser preferencialmente tratadas por sete dias.

Tratamento 10 a 14 dias: o tratamento da ITU "alta" ou "complicada" por outros fatores geralmente requer tratamento por tempo mais prolongado, 10 a 14 dias.

Pielonefrite não complicada: o tratamento de pacientes com fortes evidências clínicas e/ ou laboratoriais de infecção acometendo o tecido renal deve visar o controle ou a prevenção do desenvolvimento de sepse e das conseqüências inflamatórias da pielonefrite, além da erradicação do microorganismo e controle da recorrência precoce. Não há evidência que sugira que um antimicrobiano é superior a outro. A terapia parenteral deve ser prontamente instituída e assim que o paciente estiver afebril por 24 horas, já pode receber antibioticoterapia oral. Na realidade, o mérito da terapia parenteral diz respeito à maior rapidez com que se atingem níveis séricos adequados, e também são úteis nos pacientes com quadros acompanhados de vômitos. Não é obrigatória a escolha de um antimicrobiano de forma que o mesmo possa ser administrado inicialmente por via parenteral e depois porvia oral. Esquemas utilizando altas doses de aminoglicosídeos seguidas de ciprofloxacina por via oral têm sido sugeridos. Em pacientes com formas menos graves e sem vômitos, esquemas exclusivos por via oral de fluorquinolonas com boa penetração tecidual como a ciprofloxacina podem ser considerados.

ITU complicada: torna-se mais difícil padronizar a recomendação de antibióticos pois - espectro clínico nas ITU complicadas, com alterações anatômicas do trato urinário, é muito amplo e o tratamento irá depender da condição associada (pielonefrite, catéter, obstrução, pós-transplante renal, diabetes, etc) e do germe identificado. De maneira geral, nas infecções graves com importante comprometimento sistêmico, as cefalosporinas de $I^{\mathrm{a}}$ geração (p.ex. Cefalotina), de $2^{\mathrm{a}}$ geração, (p.ex. Cefoxitina ou Cefuroxima), de $3^{\mathrm{a}}$ geração (p.ex. Cefetamet pivoxil ou Ceftazidima ou Ceftriaxona) ou mesmo de $4^{a}$ geração (p.ex. Cefe- pima) podem ser utilizadas de acordo com o nível de gravidade. As cefalosporinas de $3^{\mathrm{a}}$ geração são altamente eficazes contra enterobactérias em geral, mas não contra Pseudomonas. Alguns germes gram-positivos como Enterococcus e Staphylococcus também são pouco sensíveis. Os aminoglicosídeos como Amicacina ou Gentamicina são bastante eficazes para germes gram-negativos, mas deve-se ter em mente o especial efeito nefrotóxico destes agentes. Quando possível, a realização do teste de gram pode auxiliar bastante na identificação da presença de enterococcus. Se gram-positivos estão presentes ou se esta informação não está disponível, deve-se associar Ampicilina endovenosa ou Vancomicina aos aminoglicosídeos. Quando somente gram-negativos estão presentes, torna-se preferencial o uso por via parenteral, desde a associação SMZ-TMP, até fluorquinolonas, aminoglicosídeos ou cefalosporinas de amplo espectro como a Ceftriaxona. Em pacientes com quadros mais complicados, história de pielonefrites prévias ou manipulação recente do trato urinário, deve ser considerado o uso de monobactâmicos como Aztreonam, ou combinação de inibidores de $b$ lactam-b lactamase como Ampicilina-Sulbactam, Ticarcilina-Ácido clavulânico ou ainda de carbapenêmicos como Imipenem-Cilastatina.

Bacteriúria assintomática: o tratamento de bacteriúria assintomática em pacientes com fatores complicadores irá depender da condição associada:

a) Gravidez: a única indicação absoluta de tratamento de bacteriúria assintomática é a gravidez, conforme mostrado no algoritmo de bacteriúria assintomática, devido ao risco da bacteriúria predispor à pielonefrite e necrose papilar. Tratamento de ITU na gravidez por dose única não é recomendado. O tratamento deve ser por no mínimo 7 dias. Os antimicrobianos que podem ser utilizados com segurança na gravidez são Cefalexina, Ampicilina, Amoxacilina e Nitrofurantoína (Macrodantina). Com a ciprofloxacina, os riscos não podem ser descartados, não devendo ser portanto recomendada. Em casos de pielonefrite, o tratamento é preferencialmente por via parenteral em nível hospitalar.

b)Diabetes Mellitus: o tratamento de bacteriúria assintomática é controverso, sendo relativa a indicação. Por outrolado, a presença de infecção pode comprometer o adequado controle glicêmico, portanto a monitorização destes pacientes torna-se importante. Cistite ou ITUnão complicada devem ser tratadas por pelo menos 10 dias. As complicações são mais freqüentes entre diabéticos conforme comentado anteriormente.

c) Transplante renal: No pós transplante imediato, em caso de bacteriúria assintomática ou de baixa contagem há indicação de tratamento, embora controversa em alguns centros. Segundo alguns autores, ITU nesta fase precoce deve ser tratada por um período mínimo de 4 semanas. Em alguns Serviços, mas não em todos, regime de antibioticoterapia profilática é preconizado por 3 a 6 meses no pós-transplante. No período tardio de followup de transplante, a monitorização de ITU é importante e a indicação tratamento é mais variável, mas cursos de 10 a 14 dias de antibiótico são suficientes. No caso de ITU por Corynebacterium urealyticum, o antimicrobiano de escolha éa Vancomicina. Deve-se ter em mente a interferência de certos antimicrobianos sobre as concentrações de ciclosporina (ex: SMZ-TMP), bem como sinergismo de nefrotoxicidade, e ajuste de dose quando da presença de insuficiência renal. Arecorrência de ITU é freqüente. $O$ relapso geralmente indica que $\circ$ tempo de tratamento não foi adequado.

d) Catéter: bacteriúria em pacientes assintomáticos em uso de catéter não deve ser tratada devido ao potencial desenvolvimento de germes resistentes, incluindo Candida sp. A prevenção éa melhor medida e inclui inserção estéril e cuidados com o catéter, remoção rápida quando for possível e uso de drenagem fechada abaixo do nível da bexiga. Coletas de urina devem ser obtidas não por desconexão do catéter e sim através de aspiração por agulha na porção distal do catéter. Alternativas para os cateteres de demora incluem a autocateterização intermitente em caso de pacientes com certa continência urinária, e também uso de cateteres supra-púbicos ou condoms urinários.

e) Homem: ITU não complicada no homem adulto jovem é rara. Portanto, devem ser avaliadas presença de anormalidades anatômicas, cálculos ou obstrução urinária, história de cateterização ou instrumentação recente, cirurgia. Afastadas estas causas associadas, o tratamento deve ter a duração mínima de sete dias. Já em caso de ITU acompanhada de febre e 
hematúria, ou em casos de recorrências com o mesmo microorganismo, deve-se considerar a possibilidade de Prostatite. Odiagnósticoéfeito com base no resultado de culturas seriadas de jato urinário inicial antes e após massagem prostática, mas deve-se ter cuidado com esta última pelo risco de bacteriemia. A prostatite aguda responde melhor às Fluorquinolonas como a Ciprofloxacina, com melhor penetração tecidual e tratamento élongo, por no mínimo 4 a 6 semanas para evitar relapso. Além dos germes habituais, após instrumentações frequentes, há grande risco de ITU por Staphylococcus Aureus para a qual devem ser utilizadas medicações antiestafilocócicas.

f) Criança: o tratamento não difere muito do preconizado no adulto, ajustadas as doses em crianças. No caso de ITU recorrente em crianças, especialmente entre as com cicatriz renal e refluxo vesico-ureteral, a profilaxia por tempo prolongado com SMZ-TMP ( $2 \mathrm{mg} / \mathrm{kg}$ ) dose em I ou 2 doses diárias do componente $S M Z$ que fornece $10 \mathrm{mg} / \mathrm{kg} /$ dose do componente TMP) ou Nitrofurantoína $2 \mathrm{mg} / \mathrm{kg} / \mathrm{dia}$.

g)Menopausa: bacteriúria assintomática não deve ser tratada com antibióticos também devido ao risco potencial de desenvolvimento de germes resistentes. Entretanto, cremes vaginais contendo estrógeno tem sido preconizados tanto para tratamento de bacteriúria sintomática quanto para ITU recorrente nesta condição $0^{15}$. A reposição estrogência restauraa atrofia da mucosa vaginal, reduz o $\mathrm{pH}$ vaginal, impedindo a colonização por enterobactérias, seguida de colonização periuretral culminando em ITU. Os cremes contendo Estriol podem ser aplicados por via intra-vaginal à noite duas vezes por semana. Seu uso deve ser monitorizado e contra-indicado em suspeita de câncer de mama ou neoplasias estrógeno-dependentes, sangramento vaginal, presença de tromboflebites ou distúrbios tromboembólicos.

h) Formas especiais de pielonefrite incluem a Tuberculose renal (TBC) que devido à dificuldade no diagnóstico pode permanecer clinicamente silenciosa fazendo parte de quadros de piúria estéril ou hematúria ou até mesmo associada à ITU por outros germes. A TBC não complicada, sensível aos esquemas habituais, pode ser tratada com cursos de dois meses de Rifampicina, Isoniazida e Pirazinamida, seguidos de quatro meses de Rifampicina, Isoniazida. A Pielonefrite xantogranulomatosa, um tipo de pielonefrite crônica bacteriana com formação de abscessos e destruição do parênquima renal causada por Proteus mirabilis ou Escherichia coli. $O$ tratamento é a remoção cirúrgica do rim, já que o diagnóstico préoperatorio é raramente feito. Outra entidade rara é a Malocoplaquia, reação inflamatória histologicamente distinta em decorrência de infeçcão crônica comumente no trato urinário com formação de placas contendo macrófagos, que se apresenta clinicamente como insuficiência renal aguda.

\section{Profilaxia}

A profilaxia de ITU está indicada principalmente em mulheres com ITU recorrente, que apresentem mais do que duas infecções por ano, ou quando da presença de fatores que mantém a infecção como cálculos. Para que se inicie a profilaxia énecessário que a urocultura se mostre negativa para evitar o tratamento de uma eventual infecção vigente com sub-dose de antibiótico.

As drogas mais utilizadas com fins profiláticos são a Nitrofurantoína, Sulfametoxazol-Trimetoprim, e as antigas quinolonas como Ácido Pipemídico ou Ácido nalidíxico. A dose sugerida é de um comprimido à noite ao deitar (o clareamento bacteriano é menor do que durante $\circ$ dia) ou então 3 vezes por semana durante 3 a 6 meses. Quando a ITU estiver relacionada com a atividade sexual pode-se prescrever um comprimido após cada relação.

Algumas recomendações para o manuseio não medicamentoso de pacientes com ITU recorrente ou com bacteriúria assintomática incluem: a) aumento de ingestão de líquidos; b) urinar em intervalos de 2 a 3 horas; c) urinar sempre antes de deitar ou após o coito; evitar o uso de diafragma ou preservativos associados a espermicida (para não alterar $\circ \mathrm{pH}$ vaginal); d) evitar banhos de espuma ou aditivos químicos na água do banho (para não modificar a flora vaginal); e) aplicação vaginal de estrógeno em mulheres pós-menopausadas. Outras medidas não medicamentosas que também têm sido sugeridas para redução de recorrência em ITU em mulheres na prémenopausa incluem: instilação vaginal de Lactobacillus Casei uma vez por semana (reducão de $80 \%$ em um estudo); acidificantes urinários tipo Mandelato de Metenamina associados ou não à vitamina $C$; ingestão de suco de "cranberry" (vaccinium macrocarpon), que supostamente inibe a expressão de fimbrias da E.coli (este suco não é disponível em nosso meio). Em estudo controlado, o consumo de suco "cranberry" e não o de lactobacilos em forma de bebida, cinco vezes por semana por um ano, reduziu a recorrência de ITU em relação ao placebo.

\section{SUMMARY}

\section{Diagnosis and Clinical management OF URINARY TRACT INFECTION}

A review about recent aspects on diagnosis and clinical management of urinary tract infection (UTI) is presented. There is a wide variation in clinical presentation of UTI which include different forms as cystitis, pyelonephritis, urethral syndrome and the clinical relevance of asymptomatic bacteriuria and low-count bacteriuria that must be distinguished from contamination. Pathogenetic aspects concerning bacterial virulence as well as host factors in susceptibility to UTI as urinary tract obstruction, vesicoureteral reflux, indwelling bladder catheters, pregnancy, diabetes mellitus, sexual activity, contraceptive methods, prostatism, menopause, advanced age and renal transplantation are discussed. Diagnostic criteria and the most common tests utilized for differentiation between lower and upper UTI have been reviewed. The authors conclude that a careful evaluation of the underlying factors is required for the correct diagnosis of UTI and to prevent recurrence and that appropriate strategies and specific therapeutic regimens may maximize the benefit while reducing costs and adverse reactions. [Rev Assoc Med Bras 2003; 49(I): 109-16]

KEYWORDS: Urinary infection. Asymptomatic bacteriuria. Cystitis. Pyelonephritis. Urethral syndrome.

\section{REFERÊNCIAS}

I. Nicolle LE. Epidemiology of urinary tract infection. Infect Med 200 I; I8: I53-62.

2. Schor N, Heilberg IP, Perrone HC, Laranja SMR, Gandolpho L, Martini LA, et al. Infecção do trato urinário inferior - cistite e síndrome uretral. Rev Bras Med 1 995; 52: 141-64.

3. Funfstuck R, Smith JW, Tschape H, Stein G. Pathogenetic aspects of uncomplicated urinary tract infection: recent advances. Clin Nephrol 1997; 47:13-8.

4. Stapleton A. Host factors in susceptibility to urinary tract infections. Adv Exp Med Biol 1999; 462:35I-8. 
5. Sillén U. Vesicoureteral reflux in infants. Pediatr Nephrol 1999; | 3:355-61.

6. RamsayJWA, GarnhamAJ, Mulhall AB, CrowRA, Bryan JM, Eardley I, et al. Biofilms, bacteria and bladder catheters. BrJUrol 1989; 64:395-98.

7. Tchoudomirova K, Mardh PA, Kallings I, Nilsson S, Hellberg D. History, clinical findings, sexual behavior and hygiene habits in women with and without recurrent episodes of urinary symptoms. Acta Obstet Gynecol Scand 1998; 77:654-59.

8. Schaeffer AJ, Rajan N, Wright ET, Duncan JL, Anderson $\mathrm{BE}$. Role of vaginal colonization in urinary tract infection (UTIs). Adv Exp Med Biol 1999; 462:339-49.

9. Nishiura JL, Heilberg IP, Perrone HC, Laranja SMR, Gandolpho L, Martini LA, et al. Infecção urinária no idoso. Rev Bras Med 1995; 52:95I-62.

10. Ferreira AC, Heilberg IP. Infecção do trato urinário no pós-transplante renal em crianças. J Bras Nefrol 200 I ;23: I 8-24.

II. Perrone HC, Cyllo AC, Heilberg IP, Laranja SMR, Gandolpho L, Martini LA, et al. Atualidades em infecção do trato urinário na infância. Pediatr Mod 1 996; 32:95- 104.

12. Franz M, HorlWH. Commonerrors in diagnosis and management of urinary tract infection I: Pathophysiology and diagnostic techniques Nephrol Dial Transplant 1999; | 4:2746-53.

13. Franz M, Horl WH. Common errors in diagnosis and management of urinary tract infection II: clinical management. Nephrol Dial Transplant 1999; 14:2754-62.
14. Lapchik MS, Nishiura JL, Heilberg IP, Pancotti SL, Ajzen H, Schor N. Tratamento da infecção urinária não complicada (ITU): estudo comparativo entre a ciprofloxacina (CIPRO) e sulfametoxazol + trimetoprima (SMZ+TMP) com 2 esquemas de duração terapêutica. JBras Nefrol 1995; 17:31-4.

15. Raz R, Stamm WE. A controlled trial of intravaginal estriol in postmenopausal women with recurrent urinary tracty infections. $\mathrm{N}$ Engl J Med 1993; 329:753-6.

Artigo recebido:06/02/2002

Aceito para publicação: 18/02/2002 